\title{
The Elephant in the Classroom: Using YouTube Comments to Address the Essential but Unacknowledged Topic of Race
}

\author{
Jacqueline Riley \\ Texas A\&M University at Commerce \\ U. S. A. \\ Laura E. Slay \\ Texas A\&M University at Commerce \\ U. S. A. \\ Carol Revelle \\ Texas A\&M University at Commerce \\ U. S. A.
}

\begin{abstract}
Drawing on critical race media theory, this praxis article describes how instructors can effectively introduce critical race literacy theory in a teacher education class using online videos. Ultimately, this study helps us to better understand how viewing YouTube videos and responding critically to YouTube user comments can help preservice teachers acknowledge and challenge their pre-existing beliefs related to teachers and students of color in a teacher education writing course. Data analysis reveals that preservice teachers' idealism for compassionate teaching is embedded in a superficial understanding of sociocultural differences and lacks an understanding of how race affects student learning.
\end{abstract}

KEY WORDS: critical literacy, teacher preparation, diversity, social media, media literacy

\author{
Literature Review \\ Praxis \\ Discussion \\ Implications \\ References \\ Author Contact
}

The expression "the elephant in the room" is a metaphorical idiom used to refer to a topic so large that everyone knows about it but avoids talking about it because it makes people feel uncomfortable. Discussion surrounding race and cultural diversity is often one such topic, particularly where racial and cultural differences are present. Multicultural scholars (DiAngelo, 2018; Singleton \& Linton, 2005) have recognized the need to forge critical conversations about race to bridge understanding across multicultural differences. Yet, social media may either mask or perpetuate the tension of uncomfortable discussion. Educators can help turn 
this tide by helping their students to notice "the elephant in the room" by developing awareness of what divides us and providing tools to facilitate discussion about uncomfortable topics about race and culture. According to Yosso (2002, citing Freire, 1973; Smith \& Alschuler, 1976), "Critical media literacy utilizes media as a pedagogical tool to facilitate students' becoming critically conscious of themselves in relation to the structures of power and domination in their world." As teacher educators in higher education, we have observed the silenced voices of our adult students of color and the superficial discussion among white students related to cultural difference in our classes; therefore, we aim to explore ways to facilitate conversations about difficult conversations related to race and culture using social media.

In today's digital world, one cannot escape social media, including YouTube. Current data underscores the website's global impact: Over two billion logged-in users access the website daily, watching over one billion hours of video (YouTube About, 2020). Numerous resources (Edutopia, National Education Association, TeachThought) offer tips for effectively selecting and using video to supplement instruction. Yet, research shows that a greater concern with social media includes the risk of reinforcing negative stereotypes, particularly for students of color. Online videos and users' comments may promote a deficit perspective and reinforce negative stereotypes (Yosso, 2002). To interrupt these patterns, teacher candidates benefit from engagements with uncomfortable conversations and texts that confront their assumptions and beliefs while providing space for dialogue and action around issues of social injustices (Baily, et al., 2014; Berger, 2004;).

Through discussions revolving around online videos and users' online comments in response to these videos, teacher candidates can address representations of the inequalities diverse students face and ways teachers can advocate for them. Because teachers are responsible for including diverse perspectives and providing space for alternative narratives, this type of critical reflection (making meaning between worldviews) provides the opportunity to interpret educational experiences and environments with new patterns of thinking and may lead to transformation (Mezirow, 1991).

The author researchers are three female teacher educators, raised with unique cultural heritages that inform their perspectives as researchers who advocate for equity in education. As the daughter of a Mexican American mother and white American father, researcher 1 speaks Spanish and English, and was educated in the U.S. Author 2 was raised speaking Spanish and English in Mexico and Chile and received her formal education in the U.S. Author 3 was raised speaking English in the south-eastern region of the United States. Although we are women with Anglicized surnames and light skin, our appearance may cause students to initially make assumptions about our identities and perspectives (e.g., they are white, rather than Hispanic/Latina).

As educators in a large rural university that serves a diverse, yet predominantly white student population $(50 \%)$, we recognize the importance of incorporating a social justice pedagogy. Because the racial and sociocultural 
makeup of our nation's school districts continues to grow in diversity (Rabinowitz, et al., 2019), we believe it is essential to prepare our teacher candidates to work across sociocultural lines by fostering a pedagogical mindset for equity and inclusivity. We also believe that critical inquiry and discussion requires the capacity to recognize and confront biased narratives about race and culture, particularly in the media. Therefore, we wanted to know, "How can instructors effectively introduce critical race literacy theory in a teacher education class using online videos and comments?" Ultimately, this study helps us to better understand how viewing YouTube videos and responding critically to YouTube user comments can help teacher candidates acknowledge and challenge their pre-existing beliefs related to teachers and students of color in our writing course. This praxis article explores how and why teacher candidates can use YouTube videos and their comments to spur meaningful discussions surrounding critical race media literacy (CRML) and ultimately help position teachers as advocates for diverse students.

In this article, we describe a multi-step protocol we developed for viewing and responding to a selected video and YouTube user comments that provided our teacher candidates an opportunity to critically engage in conversations that may challenge their own experiences by engaging them with diverse, and often polarized, counter narratives present in the selected YouTube comments. Our analysis of the data reveals the consistent themes of preservice teachers' zeal for compassionate teaching, embedded in a superficial understanding of sociocultural differences and indicators of white privilege. Our closing discussion offers ways to use social media and multimodal literacies to confront complacency and to ignite the uncomfortable conversations often found in mixed ethnic and racial settings to interrogate or navigate problematic representations of individuals, identities, and/or groups by fostering a social action pedagogy in an elementary literacy teacher preparation course. Our protocol draws on critical race theory in education (Solórzano \& Yosso, 2002) and Freire's (1973) critical literacy process which informs critical race media literacy (Yosso, 2002) as a tool to raise social consciousness.

\section{Literature Review}

\section{What is critical race media literacy?}

Critical race theory draws on the early writings of civil rights scholars Derreck Bell, Richard Delgado, Jean Stefanic, and Mari Matsuda in response to stalled progress and the rolling back of gains made from the civil rights movement (Delgado \& Stefancic, 2012). Critical race media literacy (CRML) uses critical race theory (CRT) as "a framework that can address the racism, sexism, and classism embedded in entertainment media" (Yosso, 2002, p. 53) and as a tool to raise social consciousness. Strategies for confronting racism include counterstorytelling, a method critical race theorists argue draws on the often untold stories or experiences of people of color (Solorzano \& Yosso, 2002). 


\section{Making Space in Media}

The context of media is a space of opportunity for teacher educators seeking authentic texts for engaging students in an examination of social interactions. In Berger's article, "Dancing on the Threshold of Meaning" (2004), she describes the "edge of meaning making" (p. 336) where students can find their "growing edge" (p. 336) when pushed by a transformative teacher. She suggests that the work of a transformative teacher is first to help students find the edge of their understanding, second to be company at that edge, and finally to help students construct a new, transformed place. Ultimately, she argues, this process will help students find the courage they need to transform. This supports the idea that the transformation that we want for our teacher candidates takes place in a liminal zone where teachers process their own thinking at the edges of their own knowing about potentially preconceived ideas and understandings about their future students. It also discourages abrupt and antagonistic approaches that fail to meet the learners where they are as members of the community.

\section{How Critical Race Media Theory Impacts Teacher Education}

Viewers use their own lenses to interpret media. For instance, when viewing films or television shows for pleasure or when viewing media they find relatable, their ability to critically analyze media may be affected (Tisdell, 2008). Teacher candidates encounter various media forms which shape their opinions. From the events presented and language used, local news may offer a specific version of what occurred (Kohnen \& Lacy, 2018). An unexamined viewing of media reinforces the idea of neutrality in education, where privilege is present. This is evidenced in the ongoing production of mostly white teachers who are often poorly prepared to provide an appropriate educational experience for racially/ethnically diverse students (Sleeter, 2016). To improve preparedness, Sleeter (2016) adapted a framework from Milner's work (2007) where teachers examine their own identity in relation to others' before engaging together and focusing on how teachers can improve for the group.

Many instructors in colleges of education are themselves white, preparing white teacher candidates in this critical work. Kohnen and Lacy (2018) recognize the embedded implications of whiteness when they acknowledge that "we (both of us White) are sensitive to the question of whether White scholars can employ CRT in their work without colonizing the concept. Indeed, White scholars should not presume to speak for students of color" (Bergerson, 2003, p. 104). Therefore it is important for instructors to facilitate opportunities to hear many perspectives in the classroom, including those representing diverse culture groups across teacher and student populations.

By amplifying silenced voices through counter narratives, all instructors can provide an entry point for teacher candidates to critically examine their own beliefs and how they engage with media. Encouraging students to transform extends from changing what they think to how they think, and this transformation can help students see new options they have not considered before. However, according to Berger (2004), we must also help our students deal with the "loss - a loss of 
satisfaction with their earlier perspectives" (p.340). Instructors take on the role of facilitator, offering support to teacher candidates as they examine their own beliefs and biases. It is our responsibility to support students as they transform (p. 336). In this supportive environment, we can help our students push back against harmful pre-existing educator beliefs while replacing unproductive patterns with patterns that provide a more equitable educational experience for diverse students.

The coursework required during teacher candidacy offers an opportunity to improve these patterns. Tisdell (2008) argues that it is easier to challenge assumptions about structural relationships using media in a higher education class or another organized learning setting. In such settings, whether formal or informal, the focus can be placed on examining media through a critical lens. Teacher candidates come to their coursework expecting to learn and change as they become professionals and to learn how to best guide their own students. Becoming a teacher should be a transformative experience as deeper analysis is facilitated through interaction with and about the issues presented in the media (DassBrailsford, 2007; Tisdell, 2008).

\section{How CRML Can Be Used in a Classroom}

Teacher candidates, at times, are required to watch media as part of their coursework. For example, it is not uncommon for preservice and in-service educators to watch inspiring education-themed movies, such as Freedom Writers (DeVito, et al., 2007) or Dangerous Minds (Smith, et al., 1999), and respond to discussion questions. Depending on the instructor's intent and course content, the focus may range greatly (e.g., instructional practices, family dynamics of the student). Thus, in order for teacher candidates to closely examine CRML, the instructor will likely need to provide explicit instructions, guiding questions, focused prompts, etc. Tisdell (2008) noted that the job of the facilitator is to ask questions and highlight that every film or television show portrays bias, including gender, class, race, and sexual orientation; even in media which contains only individuals of a dominant/mainstream culture as the absence of marginalized people also conveys a message.

\section{Praxis}

\section{Context}

To answer this research question: "How can instructors effectively introduce critical race literacy in a teacher education class using online video comments?", we implemented a lesson protocol within three sections of the same junior-level elementary education reading and literacy course. Researchers 2 and 3 were also the regular instructors for these sections. Due to the university's reading course offerings, students take this course either once per week (2.5 hours during the evening) or twice per week ( 1.25 hours each during the afternoon). Researcher 2 implemented the lesson protocol during her one 2.5-hour long class period; while researcher 3 implemented the same lesson protocol with two sections of the same class, but for each section divided it into two 1.25-hour class periods. Each section was taught independently. 
Researchers 2 and 3 invited all students in their section(s) to participate in the study at the end of a class period early in the semester. Each researcher emphasized that participation was voluntary and would not affect students' grades. The researchers also explained that all students would be completing the same tasks within that reading course; however, only those who had volunteered to participate would have their data used in the study. Students who agreed to participate signed and returned an informed consent form electronically. They were also assigned a random number to use in place of their names. Researcher 1, who does not teach the reading methods course, was able to access the informed consent forms and list which contained the students' names and identities. In allowing her access to participating students' identities and not researchers 2 and 3 , participants could freely complete the data without fear of judgement from their instructors.

Thirteen, 34 , and nine of the students participated in the $2.5,1.25$, and 1.25hour courses respectively. Survey data provided demographic information about the participants. For readability, when including the number of participants using percentages, we have rounded to the nearest whole number. The participants selfidentified as being of various ethnicities. The majority of participants $(90 \%)$ represented two ethnicities: Thirty-nine (70\%) identified as white and $11(20 \%)$ identified as Latino/Hispanic. Additionally, two (4\%) identified as African, two (4\%) as mixed races, $1(2 \%)$ as South Asian, and $1(2 \%)$ as Asian.

\section{The Protocol}

We developed our protocol based on prior engagements with YouTube videos and comments in a bilingual education course previously taught by two of the researchers when they used YouTube videos and comments in another class and experienced active participation. For this study, to standardize the steps, and to collect data at each step of the process, we created the following protocol.

\section{Table 1}

YouTube Video Controversies Protocol

\begin{tabular}{|l|l|l|}
\hline Protocol Step & Protocol Description & $\begin{array}{l}\text { Protocol } \\
\text { Participation }\end{array}$ \\
\hline YouTube Video Clip & Selected video clip played & Whole Class \\
\hline Survey & $\begin{array}{l}\text { Initial response to comments - } \\
\text { Agree/Disagree }\end{array}$ & Individual \\
\hline $\begin{array}{l}\text { Discussion (Repeated until } \\
\text { each comment has been } \\
\text { discussed) }\end{array}$ & Discuss comment with peers & Small Group \\
\hline
\end{tabular}




\begin{tabular}{|l|l|l|}
$\begin{array}{l}\text { Responding to Users' } \\
\text { Comments (Repeated until } \\
\text { each comment has a } \\
\text { response) }\end{array}$ & $\begin{array}{l}\text { Written response to comment on } \\
\text { a Post-it Note }\end{array}$ & Individual \\
\hline Gallery Walk & View written responses & Whole Class \\
\hline Exit Ticket Response & Reflect on learning & Individual \\
\hline
\end{tabular}

Additionally, we chose a new YouTube video clip for this course which connected to the literacy focus in the course description. We selected YouTube user comments for the protocol that included important takeaways and offered diverse opinions. We used the following considerations to select the video and accompanying YouTube user comments for the protocol.

\section{Table 2}

Criteria for Choosing YouTube Videos

\section{Criteria for Choosing YouTube Videos}

Do the users support their opinion?

Are the comments interesting?

Do the comments help students to consider an important takeaway?

Do the comments represent diverse opinions?

Both researchers followed the same protocol for choosing a YouTube video and collecting data across all three classes.

\section{Presenting the YouTube Video}

We started our protocol by asking our students to contemplate the kind of students they might expect to teach when they have their own classroom. Then, we showed them a YouTube video, a clip from the movie Freedom Writers (2007), starring Hilary Swank who played Erin Gruwell in a movie about a high school English teacher working in an inner-city high school. In this 4.20-minute clip, Grewell, the protagonist, reads her students' journals while flashbacks of her students' writing are visually played out in the background, revealing stories of violence, family dysfunction, and social strife that have presumably influenced the teenage personas in present day. 


\section{Student Survey}

After watching the clip, we asked students to use their cellphone to take a Qualtrics survey in which they indicated whether they agreed or disagreed with each of the YouTube comments below.

\section{Table 3}

Comments in Response to Video Clip from YouTube Video Trailer Freedom Writers

\begin{tabular}{|c|c|}
\hline 1. & Erin Gruwell is a good teacher. \\
\hline 2. & $\begin{array}{l}\text {...she went into a ghetto school and kids didn't respect her at first, but } \\
\text { eventually did because they saw she cared... }\end{array}$ \\
\hline 3. & $\begin{array}{l}\text {...she went into the lion's den, and she touched the students in her } \\
\text { class by reaching out and listening. }\end{array}$ \\
\hline 4. & $\begin{array}{l}\text {...my teacher didn't [like it] because the teacher was white and said } \\
\text { why does whitey have to save the day. }\end{array}$ \\
\hline 5. & ...the school was racist and wanted white teachers... \\
\hline 6. & $\begin{array}{l}\text {...this teacher never experienced what these poor minority kids have } \\
\text { to go through... }\end{array}$ \\
\hline 7. & $\begin{array}{l}\text { All teachers need to watch this movie in order to get a teaching } \\
\text { certificate. }\end{array}$ \\
\hline 8. & $\begin{array}{l}\text { They didn't had [sic] to fear, cause they had a pretty nice white lady } \\
\text { to help. }\end{array}$ \\
\hline
\end{tabular}

We told the students that these were YouTube users' comments made in response to the video trailer they had just watched. We selected comments which we thought might inspire discussion about race, equity, and social justice. Furthermore, because these comments had been chosen for their controversial nature, we anticipated students would be interested in responding to and later discussing them. Since comments were from anonymous Internet users, we hoped that students would feel comfortable challenging the opinions expressed without fear of repercussion or conflict. It was clear that several students had seen the film, and a student later shared that the film had been shown to a class in another education course. We designed this survey to be a type of anticipatory set. This preliminary thinking also gave the students a chance to see the overarching themes of the comments; in this case, the comments offered a critical analysis of the role of race in the film. 


\section{Discussing and Responding to the Users' Comments}

We organized our students into groups of three to six members to discuss each of the comments they had just responded to on the survey. During this time, we projected the YouTube users' comments on a large screen. We initially allowed three minutes for discussion about each comment and then asked students to write a response on a sticky note. When a timer sounded, students posted their written responses on a poster with the same comment. The protocol included eight YouTube user comments. The students followed the protocol of talking for three minutes before writing individual responses to the first three comments. However, as the activity progressed, we noticed that they talked less and less about each subsequent comment before posting their own responses. By the fifth round of comments, it was clear that three minutes of discussion was more than ample time for discussion. Many students began writing before the three-minute time period ended; including several students who wanted to write immediately either while discussing or without any group discussion. After noticing this trend, we quickened the pace of discussion and eventually stopped using the timer and directed students to discuss and comment at their own pace for the final two rounds. Both researchers rotated throughout the room and intentionally avoided becoming involved. Neither researcher focused on what each group actually said. Instead, they observed student interactions merely to manage the time and process, intentionally avoiding any potential influence by proximity.

Researcher 2 found that, while writing their comments, some students clearly took longer to write than others. She noted that some students even appeared reticent to write. In particular, she observed students from one table ask, "what do we write?" They seemed confused about the instructions and more interested in completing a task than engaging in thoughtful discussion. Both researchers noted, from their perspective as facilitators, that students' conversations were not as powerful as instructors had hoped. Instead, the discussions were superficial and often reverted back to what happened in the whole movie as shared by members of the table who were already familiar with the film. Rather than engaging with the comments and the counter narratives present in the clip, the students were often summarizing "what happened." Overall, students became more focused on completing the task than on the meaning of the comments we wanted them to discuss.

\section{Gallery Walk}

After the discussions and written Post-it Note responses, the students walked around the room to read their peers' comments on the Post-it Notes in a gallery walk that was created as they worked. Due to the time constraints of the class, the students were encouraged to focus on a couple of responses to comments they were particularly interested in reading rather than reading all of the comments. The students moved quietly and read for five minutes. This gave them an opportunity to read just a few of the perspectives of their peers. 


\section{Exit Ticket Response}

After reading their peers' responses in the gallery walk, the students used their phones to log in to Qualtrics for a final short reflection to the question "How do you view the movie clip or trailer after analyzing the YouTube comments?" The teacher candidates signed in with their assigned number allowing anonymous responses. Most of the students focused on the movie clip itself and responded to how it was a good movie for teachers to watch. However, seven students criticized the comments section which challenged the movie's use of a white teacher to lead the minority students to success. Still five other students appreciated the use of multiple viewpoints and spoke to the interest they had in hearing counter narratives.

\section{Researcher Reflections and Student Work}

To discover common themes, researchers 2 and 3 each independently wrote a reflection in which they synthesized their experiences implementing the protocol above and students' products (i.e., survey responses, written responses to YouTube comments, and exit-tickets). Then, they discussed themes that were present in each of the two researcher's reflections and explored implications based on critical race literacy theory.

\section{Discussion}

In the discussion which follows, we offer the researchers' interpretation of the effectiveness of implementing the protocol as a means to effectively introduce critical race literacy theory in a teacher education class using an online clip and YouTube user comments.

\section{A Caring Teacher May Not Be Enough}

Upon reviewing students' Post-it Notes written in response to the YouTube user comments, we noted several responses highlighting the importance of a caring teacher. Repeatedly, the students spoke positively about the teacher in the clip, Erin Gruwell, and celebrated the presence of a teacher who cared. In addition to many of the responses being superficial, the "caring teacher" comments supported a concern that led us to create this protocol: It is not enough that our students care, but they must also develop specific strategies for engaging with diverse or economically challenged students. The belief that a caring teacher is a good/qualified teacher not only emerged during our class, but was also frequently mentioned during our initial interviews for teacher candidates. When asked, "Why do you want to be a teacher?", a popular response among our future teachers was that they "care about," "like children," and/or "want to be a positive influence." Certainly, it is important that teachers care about their students; but, caring in and of itself is likely not enough to effectively teach our diverse student population.

\section{Video as Inspiration to Teach Diverse Learners}

It was interesting to notice that many of our students felt motivated by Erin Gruwell's dedication to working with students who were of different racial backgrounds than her own and growing up under diverse circumstances. We sensed that our students shared Gruwell's sense of idealism that novice teachers 
often feel at the beginning of their teaching careers (Steffy \& Wolfe, 2001). Several of researcher 2's students asked her where they might find the movie to watch at home. One student even approached her after class the following week to thank her for presenting the video clip. She had just begun interning as a student teacher in an inner-city elementary school while simultaneously taking this course. She explained that she had experienced doubts about her career choice when she observed how rude the third graders were behaving in her mentor's classroom. The video clip inspired her to realize that she might be able to make a difference in the lives of diverse students if she built relationships to show how much she cared about them.

\section{Ignoring the Elephant in the Classroom}

White teachers choosing to avoid taking a stance or professing a lack of knowledge regarding race is nothing new (Garrett \& Segall, 2013; Pabon \& Basile, 2019). Similarly, in our own study, we observed students' resistance to discussing the issue of race, which was manifested in the following two ways: 1) expressing that race does not matter and 2) not taking a stand by responding with vague/superficial comments. Although the comments demonstrated empathy for the underprivileged circumstances experienced by the students depicted in the movie clip, several students expressed "race shouldn't matter," or asked, "Why does her skin color matter?" Still, another student commented that, any teacher, regardless of race, "can save the day if teaching is their [his/her] passion."

Rather than expressing the idea that race does not matter, other students responded with vague/superficial responses. For example, one student noted, "Everyone is going to have their own assumptions when it comes to watching a movie or trailer. But everyone is entitled to their own opinion." This avoidance in naming the issue may relate to a lack of knowledge, a lack of community in the classroom, or perhaps a lack of the required tools necessary to speak about difficult or controversial ideas with a group of peers from diverse races and ethnicities. When a student writes a comment with little depth, such as, "I feel like some people can be very closed minded" and, "it's interesting to see everyone's perspective," we are reminded of how difficult it is for diverse groups to talk about race and cultural differences. In any case, comments such as these fail to acknowledge the impact a teacher's race may have on teaching students of color, which can be problematic. Instead, educators must strive to not only acknowledge students' diversity, but also utilize culturally responsive teaching, which has been shown to increase student performance and engagement (Abacioglu, et al., 2019).

Although we recognize that many of the Post-it Note responses were too brief to discern depth of meaning, we perceived a general feeling of tension across the spectrum of responses. It was as though students were not sure how to respond to the YouTube users' comments or express what they might really think individually about issues of race and diversity. The tension we are referring to includes the personal discomfort one feels in the absence of knowledge and understanding. Although the concept of tension is often associated with a constrained sense of negativity, systems thinking about human dynamics claims that tension is indeed necessary and useful for change to occur (Patterson \& 
Holladay, 2018). In some cases, the student Post-it Notes did not even mention race, poverty, or violence. When a third of students in our classes are students of color, we wondered why so many of the sticky notes avoided mentioning race or poverty. Perhaps our students also felt the presence of the metaphorical "elephant in the room."

In fact, only a couple of students acknowledged that a movie celebrating a white woman coming into a community where she had never lived and turning around the lives of poor and minority students should be critically analyzed, even when the YouTube comments specifically named concerns from diverse viewpoints. Instead, the students demonstrated a lack of perspective for a counter narrative to the single-story present in most media representations of struggling urban schools.

\section{But I Won't Be Teaching Those Students}

The Post-it Note comments also indicated a sense of otherness. When the students responded to whether all students should be required to watch this film, a few students $(<10 \%)$ shared that not all teachers should be required to watch it because "some teachers won't work in this environment." Across these particular responses, there was a sense that first, struggling students are present in isolated schools in urban centers, and second, that teachers have a choice about whether to work with this population because only desperate teachers would go to a struggling urban school. This observation is similar to Ladson-Billings's (1999), who noted the problem of preservice teachers not wanting to teach in schools that were different from their own experiences. In this study, this theme was also present in some responses that included a stereotype that urban schools struggle to fill teacher vacancies and have to hire whoever applies. This is disheartening and ill-informed as the number of children in poverty is growing. The attitude of avoiding students who struggle perpetuates an unequal and segregated society that we, as educators, should be challenging.

\section{Implications}

Our observations of students' responses to the implementation of the protocol described informs our decision making. Our findings highlight the need to work with our students to help them analyze the texts and media they consume. They also underscore the benefits of exposing students to more counter narratives than their own experiences. Such interventions will help them to be better prepared to educate the diverse K-12 students they will likely encounter. We want our students to adopt inclusive teaching practices, which occur with a higher propensity when educators endorse multiculturalism and eschew colorblindness (Aragón, et al., 2017). It will also be important for us to require our teacher candidates to examine the demographics of the school districts in our region so that they realize the presence of diverse and poor students in all of our schools and appreciate their responsibility to meet these students with more than a caring attitude, although caring is a good starting point.

In this literacy class, we will pursue inquiries into what a caring teacher does to help diverse students be successful readers and writers; explore what barriers 
are present in our instruction and resources that disconnect students from texts; and discover what specific strategies we might incorporate for those learners who are not being successful. When we talk about building relationships and making connections, we should start with our words and our actions. We can care for our students by analyzing their interactions with each other, the curriculum, and resources in the classroom. Who has the voice and representation? Who does not? And in these conversations, we will start talking about how our assumptions as teachers impact our minority students so that we do not contribute to a system that silences them.

Given our students' focus on completing the product (i.e., the survey, written responses to comments, or exit ticket) rather than the process (i.e., the discussion), we see the need to adapt the protocol to better promote meaningful conversations. We realize that our protocol can only be successful if students take advantage of opportunities to collaboratively analyze the videos and YouTube comments as they relate to race and other meaningful topics surrounding education. To help promote such authentic discussions when implementing the protocol in the future, we will clearly explain the importance of and expectations for group discussion. Providing additional probing questions could also serve to draw students' attention to the deeper issues central to the lesson. Finally, we must be cognizant of the time needed to engage in meaningful discussion and, consequently, provide students with ample time to have these conversations.

\section{References}

Abacioglu, C., Volman, M., \& Fischer, A. (2019). Teachers' multicultural attitudes and perspective taking abilities as factors in culturally responsive teaching. British Journal of Educational Psychology, 90(3):736-752. https://doi.org/10.1111/bjep.12328

Aragón, O. R., Dovidio, J. F., \& Graham, M. J. (2017). Colorblind and multicultural ideologies are associated with faculty adoption of inclusive teaching practices. Journal of Diversity in Higher Education, 10(3), 201-215. doi:10.1037/dhe0000026

Baily, S., Stribling, S. M., \& McGowan, C. L. (2014). Experiencing the "Growing edge." Journal of Transformative Education, 12(3), 248-265. https://doi.org/10.1177/1541344614544373

Berger, J. G. (2004). Dancing on the threshold of meaning: Recognizing and understanding the growing edge. Journal of Transformative Education, 2(4), 336-351. https://doi.org/10.1177/1541344604267697

Bergerson, A. A. (2003). Critical race theory and white racism: Is there room for white scholars in fighting racism in education? Qualitative Studies in Education, 16(1), 51-63. https://doi.org/10.1080/0951839032000033527

Dass-Brailsford, P. (2007). Racial identity change among white graduate students. Journal of Transformative Education, 5(1), 59-78. https://doi.org/10.1177/1541344607299210 
Delgado, R, \& Stefancic, J. (2012). Critical race theory: An introduction (2 ${ }^{\text {nd }}$ ed). New York University.

DeVito, D., Schamberg, M., \& Sher, S. (Producers), \& LaGravenese, R. (Writer), \& LaGravenese, R. (Director). (2007). Freedom writers [DVD]. Paramount Pictures.

DiAngelo, R. (2018). White fragility. Beacon Press.

Freire, P. (1973). Education for a critical consciousness. Seabury.

Garrett, H. J., \& Segall, A. (2013). (Re) considerations of ignorance and resistance in teacher education. Journal of Teacher Education, 64(4), 294-304. https://doi.org/10.1177/00224871134877

Kohnen, A.M. \& Lacy, A. (2018). "They don't see us otherwise:" A discourse analysis of marginalized students critiquing the local news. Linguistics and Education, 46, 102-112. https://doi.org/10.1016/j.linged.2018.07.002

Ladson-Billings, G. J. (1999). Preparing teachers for diverse student populations: A critical race theory perspective. Review of Research in Education 24, 211247. https://doi.org/10.2307/1167271

Mezirow, J. (1991). Transformative dimensions of adult learning. Jossey-Bass.

Milner, H. R. (2007). Race, culture, and researcher positionality: Working through dangers seen, unseen, and unforeseen. Educational Researcher, 36(7), 388-400. https://doi.org/10.3102/0013189x07309471

Pabon, A. J. \& Basile, V. (2019). Can we say the "r" word?: Identifying and disrupting colorblind epistemologies in a teacher education methods course. Educational Studies, 55(6), 633-650. doi:10.1080/00131946. 2019.1674312

Patterson, L. \& Holladay, R. (2018). Deep learning ecologies: An invitation to complex teaching and learning. Human Systems Dynamics Institute.

Rabinowitz, K., Ememdjomeh, A., \& Meckler, L. (2019, September 12). How the nation's growing racial diversity is changing our schools. The Washington Post. https://www.washingtonpost.com/graphics/2019/local/schooldiversity-data/

Simpson, D., \& Bruckheimer, J. (Producers), \& Bass, R. (Writer), \& Smith, J. N. (Director). (1995). Dangerous minds [DVD]. Buena Vista Pictures.

Singleton, G.E. \& Linton, C. (2005). Courageous conversations about race: A field guide for achieving equity in schools. Corwin Press.

Sleeter, C. E. (2016). Critical race theory and the whiteness of teacher education. Urban Education, 52(2) 155-169. https://doi.org/10.1177/ 0042085916668957

Smith, W. A. \& Alschuler, A. S. (1976). How to measure Freire's stages of conscientization: The $C$ code manual. University of Massachusetts: Social Literacy Project. 
Solórzano, D.G. \& Yosso, T.J. (2002). Critical race methodology: Counterstorytelling as an analytical framework for education research. Qualitative Inquiry, (8)1, 23-44. https://doi.org/10.1177/107780040200800103

Steffy, B. E. \& Wolfe, M. P. (2001). A life-cycle model for career teachers. Kappa Delta Pi Record, 38(1), 16-19, DOI: 10.1080/00228958.2001.10518508

Tisdell, E. J. (2008). Critical media literacy and transformative learning: Drawing on pop culture and entertainment media in teaching for diversity in adult higher education. Journal of Transformative Education, 6(1), 48-67.

YouTube About. (2020, February, 29). YouTube for Press. Retrieved https://www.youtube.com/about/press/

Yosso, T. J. (2002) Critical race media literacy: Challenging deficit discourse about Chicanas/os. Journal of Popular Film and Television, 30(1), 52-62.

\section{Author Contact}

Jacqueline Riley, jacqueline.riley@tamuc.edu

Texas A\&M University at Commerce, Curriculum and Instruction

PO Box 3011, Commerce, TX 75429-3011 U. S. A.

Laura E. Slay, laura.slay@tamuc.edu

Texas A\&M University at Commerce, Curriculum and Instruction

PO Box 3011, Commerce, TX 75429-3011 U. S. A.

Carol Revelle, carol.revelle@tamuc.edu

Texas A\&M University at Commerce, Curriculum and Instruction

PO Box 3011, Commerce, TX 75429-3011 U. S. A. 